\title{
PAMPA: TERROIR DO GADO BOVINO?
}

Resumo: Este trabalho visa avaliar as transformações nos sistemas de produção da atividade pecuária bovina de corte de sua origem até o momento, com ênfase na pecuária bovina do Pampa uruguaio e argentino, e da região da Campanha gaúcha, porção do Pampa brasileiro. Centro das modernizações, bem como formador de uma identidade regional e territorial, o Pampa se coloca como uma marca identitária da produção bovina única no mundo. As recentes inovações na atividade pecuária bovina territorializam a vanguarda da modernização técnica. Associada à lavoura, verticaliza o processo produtivo consolidando laços dentro e fora do país com diferentes formas de capital internacional, tanto na produção como nas novas formas de consumo, redefinindo a inserção da atividade pecuária de corte no agronegócio, bem como a dinâmica no mercado interno e externo e a exclusividade do lugar.

Palavras-chave: Pampa. Modo de Vida. Gaúcho. Bovinocultura. Terroir.

\section{PAMPA: TERROIR OF BOVINE CATTLE?}

Abstract: This paper aims to assess changes in the production systems of the beef cattle industry from its origins to the present day, with emphasis on bovine cattle breeding in the Uruguayan and Argentine Pampa and in the Campanha gaúcha region, in the Brazilian Pampa. A center of modernization that also forged a regional and territorial identity, the Pampa is a unique mark of identity of bovine production in the world. Associated with farming, this activity verticalizes production, establishing ties in and outside Brazil with different forms of international capital, both in the production and in new forms of consumption, redefining the insertion of the beef cattle industry in agribusiness, as well as the dynamics of the domestic and foreign markets and the uniqueness of the region.

Keywords: Pampa. Lifestyle. Gaucho. Bovine culture. Terroir.

\section{PAMPA: ¿TERROIR DE GANADO VACUNO?}

Resumen: El objeto de este trabajo es evaluar las transformaciones en los procesos productivos de la actividad ganadera bovina desde su origen hasta el momento, con énfasis en la ganadería bovina de las pampas uruguaya y argentina y de la región de Campaña gaucha, porción de la pampa en la parte sur de Brasil. Centro de las modernizaciones así como formadora de identidad regional y territorial, la Pampa se erige como una marca identitaria de una producción bovina única en el mundo. Junto con el cultivo, verticaliza el proceso productivo y consolida los vínculos dentro y fuera del país con distintas formas de capital internacional, sea en la producción o en nuevas formas de consumo, redefiniendo la inserción de la actividad pecuaria de corte en la industria agropecuaria, así como la dinámica en el mercado interno y externo y la exclusividad del lugar.

Palabras clave Pampa. Modo de Vida. Gaucho. Ganadería Bovina. Terroir.

\footnotetext{
${ }^{1}$ Universidade Federal do Rio Grande do Sul, Departamento de Geociências, Porto Alegre, Brasil, luizfernandomazzini@gmail.com, https://orcid.org/0000-0002-4455-8861
} 


\title{
Introdução
}

\author{
Ningún animal doméstico, sin exceptuar el caballo; \\ ninguna nueva planta, ni siquiera el trigo, \\ produjeron en el Río de La Plata revolución semejante \\ a la causada en las costumbres por la introducción del vacuno. \\ Emilio A. Coni
}

O rebanho bovino esteve presente nas Américas onde foi fundamental na ocupação territorial, formando pastagens e assentando comunidades pastoris que se confundiram com a forma de gerir este território.

Ao longo do tempo gerou diferentes modos de vida, onde a forma do pastoreio e suas técnicas influenciam na densidade populacional, no crescimento das cidades em seu entorno, no tipo de organização da sociedade. A territorialização e a associação de diferentes técnicas de produção é a causa principal dos diferentes níveis de desenvolvimentos regionais.

O objetivo deste trabalho é o de avaliar as transformações nas formas de produção na atividade pecuária bovina de corte (sistemas de produção), de sua origem até o momento, com ênfase na pecuária bovina dos Pampas uruguaio e argentino, e da região da Campanha gaúcha, porção do Pampa brasileiro. Este, o epicentro das modernizações, bem como formador de uma identidade regional e territorial, colocando o Pampa como uma marca identitária da produção bovina única no mundo.

Esta pesquisa justifica-se pela importância da participação econômica e geográfica desta atividade na organização de desenvolvimento territorial na nossa formação socioeconômica, logo, formação espacial. As recentes inovações na atividade pecuária bovina territorializam a vanguarda da modernização técnica. Associada à lavoura, verticaliza o processo produtivo consolidando laços dentro e fora do país com diferentes formas de capital internacional, tanto na produção como no consumo, redefinindo a inserção da atividade pecuária de corte no agronegócio, bem como a dinâmica no mercado interno e externo.

Para caracterizar a agricultura, ou seja, o resultado do trabalho social sobre a terra, é importante diferenciar os cultivos (a lavoura) e a criação (a pecuária) em cada tempo, pois as mudanças técnicas são variáveis de difícil visualização, como os seus atores e território. É neste sentido que a análise da paisagem e dos sistemas de produção vem a contribuir para os estudos geográficos, pois o objetivo é descobrir o equilíbrio entre a organização e a divisão do trabalho social, da técnica utilizada e o meio, no sentido de identificar os sistemas de produção e os sistemas 
agrários a partir das marcas deixadas na paisagem. O primeiro, o sistema de produção, segundo Mazoyer e Roudart:

[...] se define pela combinação (a natureza e as proporções) de suas atividades produtivas e de seus meios de produção. A categoria social de um estabelecimento se define pelo estatuto social de sua mão de obra (familiar, assalariada, cooperativa, escrava, serviçal), pelo estatuto do agricultor e pelo seu modo de acesso à terra (livre acesso às terras comunais, reserva senhorial, posses servis, exploração direta, parceria, arrendamento...) e pela dimensão do estabelecimento agrícola (MAZOYER; ROUDART, 2010, p. 73).

Já numa escala de vila ou região, deve ser utilizado o conceito de sistema agrário, segundo os autores:

O sistema agrário pode ser conceituado como o instrumento intelectual que permite apreender a complexidade de toda forma de agricultura real pela análise metódica de sua organização e de seu funcionamento. Esse conceito permite também classificar inúmeras formas de agricultura identificáveis no passado ou observáveis no presente em um número limitado de sistemas, caracterizados cada um por um gênero de organização e funcionamento. A teoria da evolução dos sistemas agrários é o instrumento que permite representar as transformações incessantes da agricultura de uma região do mundo como uma sucessão de sistemas distintos, que constituem as etapas de uma série histórica definida. Enfim, a teoria da diferenciação dos sistemas agrários é o instrumento que permite apreender suas grandes linhas e explicar a diversidade geográfica da agricultura em uma dada época (MAZOYER; ROUDART, 2010, p. 76).

Portanto, é um conjunto de relações que se estabelecem entre as explorações e o espaço que utilizam. O sistema agrário é a expressão espacial da associação de produção e técnicas colocadas em prática por uma sociedade para satisfazer suas necessidades. Exprimem, em particular, a interação entre um sistema bioecológico representado pelo meio natural e um sistema sociocultural, através de práticas oriundas especialmente da aquisição técnica ou acumulação do conhecimento.

A produção agrícola depende, pois, de uma adequação ao ambiente e do conhecimento do grupo que a produz. Mais uma variável se soma às demais neste momento: a relação com o mercado. Variáveis como distância, grau de investimento em técnicas, preço, transporte, conservação ou perecibilidade dos produtos, entre outras, entram na distribuição espacial da produção.

Já o modo de vida ou gênero de vida, para Max Sorre:

Entende-se gênero de vida por um conjunto coletivo de atividades transmitidas e consolidadas pela tradição, graças às quais um grupo humano assegura sua existência em um meio determinado. Um conjunto de técnicas adaptativas do homem e do meio, no que comportam de elementos mentais e intelectuais. O gênero de vida oferece o máximo de estabilidade em sociedades submetidas à tirania de um meio natural muito especificado (criadores nômades do deserto, esquimós). À medida que os homens vão se emancipando dessa sujeição à natureza, o centro da vida se desloca, a 
noção de gênero de vida se preenchendo - como acabamos de sugerir - de elementos sociais (MAX SORRE, 1967, p.140).

Este conjunto de técnicas pode permanecer mais ou menos tempo. Da mesma forma, as transformações podem acontecer em menor ou maior tempo. $\mathrm{O}$ fato é que estão em permanente mudança e tendem, como são próprias dos seres humanos, a transformações, rupturas, inclusões de formas externas. Contudo, buscam superar os limites encontrados na natureza através de técnicas que proporcionem a manutenção do grupo, prosperidade ou acumulação. De qualquer forma, um tipo de estabilidade frente à instabilidade característica do meio.

O Terroir se define como a "unidade espacial que reúne diversos componentes da paisagem, ou seja, os fatores que compõem o meio, os dispositivos mais ou menos perenes que demarcam a ocupação do território e as marcas das práticas agrícolas que diferenciam os sistemas agrários desenvolvidos no decorrer do tempo".

\section{Da introdução da bovinocultura até as charqueadas}

Quem introduziu o gado vacum na Banda Oriental do Uruguai, formada por toda a terra abarcada pelo arco da margem esquerda ou Oriental do Rio Uruguai, portanto, todo o estado do Rio Grande do Sul e o Uruguai, é menos importante do que quem de fato expandiu os rebanhos e qual sua estratégia naquele momento (BRUXEL,1961, p. 165-7). Na busca pela expansão do gado bovino na Banda Oriental, esse autor conclui que entre os anos 1628-30 houve um aumento da bovinocultura até os anos 1634, parte dos animais comprados nas Vacarias, conforme documentação dos jesuítas. Entretanto, a partir de 1637 começam as invasões dos bandeirantes, o que obriga os jesuítas e os índios cristãos a se refugiarem na Banda Ocidental, abandonando os rebanhos.

Em 1641 é travada a batalha de Mbororé, na qual os índios, desta vez armados com armas de fogo, expulsam os bandeirantes que não retornam a disputar este território. Este marco é muito importante em suas consequências.

Primeiro, marca o fim da União Ibérica (1580-1640) e, por esta razão, o exército guarani recebe permissão da Coroa de Espanha para o ataque armado. Por outro lado, faz com que a estratégia dos portugueses lagunistas avance pelo litoral até fundar Laguna (1676) e Colônia do Sacramento (1680) logo em seguida. A partir daí, os jesuítas retornam para a Banda Oriental e fundam os Sete Povos das Missões. 
Este período, de 1641 a 1750, é o período áureo das Missões Jesuíticas, chegando a 30 povos no total, considerando os territórios hoje divididos entre Paraguai, Argentina e Brasil (BRUXEL, 1978).

Nesse período a população missioneira tem seu maior crescimento e também desenvolve o sistema de produção de criação do gado bovino, bem como da lavoura. "O milho, que formava com o trigo, o centeio e o arroz, a base da alimentação, dava até quatro colheitas por ano" (LUGON, 1976, p.125). Os índios colhiam a erva-mate, que era abundante, mas também a plantavam próximo à redução. A erva era o principal produto comercializado pelas Missões. "As estâncias estendiam-se por centenas de hectares. Eram cercadas de muralhas, de cercas vivas de cactos, de sebes ou valados. Cada estância estava dividida em vários distritos ou rodeos, contendo, cada uma, cinco a seis mil cabeças de gado" (LUGON, 1976, p.128). Também criavam muitos cavalos, mulas e ovelhas, estas para a obtenção de lã.

Bruxel (1978, p.115) "entende por vacaria o campo onde se cria gado vacum selvagem, ao passo que estância é o campo de criação de gado, aos cuidados do homem." Para este autor, a pecuária bovina supria de proteínas, importante alimento segundo os jesuítas, e abastecia a população nos tempos de seca, quando as lavouras diminuíam a sua produtividade. Utilizavam para demarcá-las obstáculos naturais, como banhados, rios e matos intransponíveis, além da construção de valas. Com isto foi possível separar os cavalos xucros de vacas e ovelhas prenhas. "Os posteiros eram famílias indígenas, encarregadas de evitar a evasão do gado e de efetuar rodeios, para amansá-los e acostumá-los à vista do homem a cavalo, com a finalidade de facilitar sua futura remoção para as invernadas." (BRUXEL, 1978, p.117). De tempos em tempos, um rebanho era levado para as proximidades das reduções para as reses irem sendo abatidas conforme a necessidade.

Cada grupo de aldeias era responsável pela manutenção da sua estância onde o gado era comunal - e da terra. Este sistema de produção pecuário seguiu muito semelhante até os tempos das charqueadas, já na estância privada. Com a introdução das raças europeias, e a necessidade do alambrado, foram dispensados o posteiro e sua família, diminuindo a população no campo e aumentando a da periferia das escassas e frágeis cidades.

A partir do Tratado de Madri e da expulsão de padres e índios, o sistema comunal entra em decadência. Mas não especificamente o sistema da bovinocultura. Este é apropriado, ou seja, terra, gado e trabalho (peão) pelos concessionários da 
terra, concedido pela Coroa de Espanha a partir de Montevidéu, por um lado, e o sistema sesmarial português, por outro. A fundação de Colônia do Sacramento significa muito mais que um posto de contrabando. O contexto de interesses lusos e ingleses, franceses e holandeses se costura junto com a expansão ganadeira.

Referir-se à Colônia do Sacramento como um posto de contrabando é verdadeiro. No entanto, isto é apenas a ponta do iceberg. O contexto da sua fundação e suas alianças é bem maior e define o destino da Banda Oriental do Uruguai desde a fundação de Buenos Aires.

Para Cacciatore (2017, p.24), tudo começa com a indefinição do Tratado de Tordesilhas, de 1494, que "não definiu a ilha do arquipélago de que partiria a medição e tampouco a medida das léguas", ou seja, a Banda Oriental do Uruguai ficou na faixa de maior indefinição e, portanto, de contestação. A estratégia portuguesa era avançar no rumo oeste, pelo menos até a margem direita do rio Amazonas, a margem esquerda dos rios Paraná e Uruguai, formando, assim, a llha Brasil. A União das Coroas de Portugal e Castela (Ibéricas) pôs sob o mesmo domínio vastos territórios do novo mundo.

Este período coincide com a segunda fundação de Buenos Aires, resultado do aumento da atividade comercial que abastecia Potosí, a cidade mais alta do ocidente, com uma atividade mineradora intensiva de prata, demandadora de produtos altamente inflacionados por uma população grande e carente de produtos, de alimentos a vestuário. "Potosí só podia viver graças aos gêneros importados dos vales vizinhos", tornando-se, assim, "o mercado mais caro do mundo" (CANABRAVA, 1984, p.36). A mão de obra também era insuficiente, principalmente para o trabalho pesado das minas. Isso alimentou e desenvolveu uma intensa atividade comercial no Rio da Prata, fazendo de Buenos Aires um porto estratégico.

A mineração do Alto Peru intensificou o comércio de mulas, vinhos da região de Cuyo (Mendoza e San Juan), linho, algodão, erva-mate e carretas de madeira e roda grande para atravessar os terrenos pantanosos. Entretanto, as províncias do Rio da Prata e de Tucumán não possuíam riquezas minerais, não participando do comércio entre a colônia e a metrópole, apenas do mercado regional. Para Canabrava (1984), esta região do Rio da Prata vai ganhar importância após a fundação da Audiência de Chacras, em 1561, que visava à formação de uma grande unidade administrativa que compreenderia Potosí, Tucumán e o Paraguai, com um porto no Rio da Prata pelo rio Paraná. Desta forma, Assunção comunicava-se diretamente com o Rio da Prata. 
O aumento da demanda de couro e sebo na região levou ao crescimento do consumo do gado da margem direita do rio Paraná, esgotando rapidamente os rebanhos buenairenses e santafesinos. Neste período, por diversas vezes, houve restrições ao abate de reses. As disputas alfandegárias entre Córdoba e Buenos Aires restringiam o comércio e as importações de produtos desta última. Diversas licenças de ampliação da atividade comercial para a liberação do porto de Buenos Aires foram solicitadas nessa época.

A proibição foi estimuladora do contrabando, trazendo à cena platina um novo e importante personagem:

\begin{abstract}
Pouco depois o bispo de Chacras denunciava a quantidade de negros que entravam pelo porto sem licença, justamente com estrangeiros diversos, particularmente portugueses. A Audiência solicitava providências para proibir a entrada da gente de nação portuguesa [...] que penetrava pelo Rio da Prata e se infiltrava nos territórios do Alto Peru. Além de escravos que chegavam procedentes do Brasil, ativo comércio de gêneros alimentícios e produtos manufaturados se fazia entre os portos brasileiros e o Rio da Prata (CANABRAVA, 1984, p. 87).
\end{abstract}

Potosí consumia rapidamente a população indígena e demandava mais escravos trazidos pelos portugueses, especialistas no tráfico de escravos e na navegação do estuário do Prata. Assim, o combate ao contrabando foi vencido pela legitimidade da necessidade consumidora de Potosí. Os portugueses foram se estabelecendo no comércio em Buenos Aires com práticas ilícitas, já com a discreta colaboração dos ingleses. "Pelo fato de estar em mãos portuguesas o comércio de negros, Lisboa pôde desempenhar papel importante em relação ao comércio de contrabando com as colônias espanholas" (CANABRAVA, 1984, p.119). Os navios que partiam, ou retornavam para Buenos Aires, tinham que fazer uma parada estratégica, fosse em São Vicente, Rio de Janeiro ou Pernambuco, o que facilitava as trocas, principalmente as proibidas.

Entretanto,

No segundo quartel do século XVII, quando se iniciou, como mostraremos adiante, a decadência do comércio luso-brasileiro com o Rio da Prata, uma nova área das terras de Castela começou a ser procurada pelos mercadores lusos, isto é, o atual território do Rio Grande do Sul. O Prof. Ellis Junior, depois de paciente pesquisa nos documentos impressos nas Atas, conseguiu fixar a data de 1635 para o início da expansão dos sertanistas planaltinos nas províncias jesuíticas do Uruguai e do Tape, ano em que a bandeira paulista esteve no sertão dos Patos (CANABRAVA, 1984, p. 136).

Mais adiante,

Esse fato nos indica que os esforços de infiltração comercial portuguesa na região ao norte do Rio da Prata deviam ter encontrado forte oposição por parte 
dos jesuítas que iniciavam então o estabelecimento das aldeias indígenas que formaram as Províncias do Tape e do Uruguai (CANABRAVA, 1984, p. 137).

No ano de 1640 finda a União Ibérica e as disputas territoriais voltam ao seu normal. Em 1680, os portugueses fundam a Colônia do Santíssimo Sacramento para continuarem as práticas de contrabando que desenvolviam em Buenos Aires, só que agora com a companhia mais acentuada dos ingleses, franceses e holandeses, e tendo toda a Vacaria do Mar para explorar o couro tão demandado pela fabricação de correias na manufatura inglesa.

Enquanto a vida nas reduções jesuíticas corria normalmente entre os seus muitos afazeres, lentamente, pelo sul e pelo norte, começa o processo de concessão de terras pelas Coroas portuguesa e espanhola. A primeira começa em 1732 pelo litoral, aproximadamente onde se encontra a praia de Tramandaí.

Uma parcela de sesmaria tinha aproximadamente 13 mil hectares, destinados à atividade pecuária bovina. Uma data correspondia a 272 hectares, destinados aos pequenos agricultores.

A atividade charqueadora deve ter começado em torno do que hoje é a praia do Quintão, mais especificamente em Palmares do Sul, indo em direção às margens do Guaíba e no baixo Jacuí, sendo este charque levado até o porto de Laguna para ser transportado para o centro do país, visto que a Barra do Rio Grande somente foi fortificada em 1737 (MARQUES, 1987,60-1). Em 1779, José Pinto Martins estabelece sua indústria de charque às margens do Rio Pelotas. Segundo Marques $(1987,85)$, esta atividade desenvolveu bastante a navegação fluvial, gerou muitos empregos e estimulou o comércio regional, embora tenha causado o fim das grandes tropeadas.

O local de fornecimento nem sempre foi regular. Conforme as condições da fronteira passava gado brasileiro para o Uruguai ou deste país para o abastecimento das charqueadas locais, via o incontrolável contrabando que sempre aconteceu por estes pagos. Depois de estabelecida a pecuária na Região do Planalto Riograndense, também estes forneciam gado para os saladeiros. Tanto o rebanho do litoral quanto o do Planalto gaúcho tinham seu preço depreciado em relação ao da região da Campanha, sempre em troca com o uruguaio, mais adiantado no melhoramento do gado.

A elevação de tarifas do produto platino estimulava o contrabando. Os países platinos, sob a égide da Inglaterra, construíram estradas de ferro, portos modernos, e, em função de obter maior rendimento do trabalho assalariado, introduziram sempre 
artefatos que possibilitassem um aumento no rendimento do trabalho. Nos países do Prata a pecuária era a principal atividade econômica para exportação, recebendo por isto mais estímulos.

As estâncias de gado que se constituíram realizavam pecuária extensiva do rebanho, utilizando como mão-de-obra peões. Estes eram elementos subalternos do antigo bando armado que tropeava gado ou índios egressos das missões. Embora se registrasse o uso de escravos nas estâncias, a atividade de criação, subsidiária da economia central do país, não foi capaz de propiciar uma acumulação que permitisse a introdução regular de negros na região. Estes não se constituíram na mão-de-obra fundamental no processo de trabalho (PESAVENTO, 1994, p.15). (Grifo nosso)

A estância nacional se caracterizava por baixos investimentos, tanto na obtenção da terra como da sua mão de obra. Entretanto, a defesa da estância garantia a estratégia portuguesa de ocupação e consolidação da fronteira.

De qualquer maneira, a genética do bovino destinado às charqueadas ainda é a do rebanho rústico, ou chimarrão (cimarrón), no qual a espessura do couro e a quantidade de sebo são mais importantes que a qualidade da carne. O tempo ideal de abate era de oito anos, quando o bovino atinge o seu maior crescimento. $O$ sistema de produção nas charqueadas pouco difere daquele da estância missioneira, e o melhoramento na região da Campanha muito deve às "trocas" com o lado uruguaio. Nestas bases se consolida o latifúndio e a sua correspondente sociedade latifundiária.

A respeito da estância colonial, Gilberti (1986, p. 45) escreve que, pelo lado castelhano, cada colono fundador recebia en merced uma quantidade de terra segundo sua condição. Os peões receberiam uma peônia, de dimensões reduzidas. Já para os oficiais ou pessoas que ganhavam por serviços prestados, a parcela quintuplicava e correspondia a uma caballería. Todos deveriam edificar e ocupar a casa, lavrar e povoar de gado a terra. Os lotes maiores chamavam-se suerte de estancia e tinham 1.875 ha. Em síntese, coloca o autor, os fundadores recebiam pequenas parcelas, enquanto militares e funcionários de alta categoria obtinham extensões maiores e livres de todas as obrigações. Com isto estimulava-se a formação do latifúndio em grande escala, com o objetivo de criar um tipo que defenda a terra em nome de quem lhe dá a legitimidade da posse.

Para Williman e Pons (2011, p. 27-8), fundada a cidade de Montevidéu, em 1724, começaram a demarcação e a distribuição de terras para seus antigos povoadores. Preferencialmente, a repartição se consolidou pela suerte de estancia, concentrando grandes glebas de terra. 
A distribuição de terras se deu a partir de Montevidéu em direção a Vacaria do Mar, ocupando a margem esquerda do Rio Negro, que corta em diagonal o Uruguai na direção sudoeste-nordeste. Por sua vez, à margem direita deste rio, até o noroeste do Rio Grande do Sul, se encontravam as terras comunais das Missões Jesuíticas, suas estâncias ao sul e as reduções ao norte, ocupando todo o quadrante oeste da Banda Oriental. Pelo sul, a partir de Montevidéu, caminhavam as estâncias privadas de Espanha; pelo norte, litoral e Viamão-Porto Alegre, os sesmeiros lusos. Em algum momento haveriam de se encontrar e disputar as terras do quadrante oeste, ou seja, jesuítico-guarani.

Foi neste vazio de castelhanos e lusos, em meio a Vacaria do Mar, que se fez necessária a presença de um intermediário para os negócios lusitanos de Colônia do Sacramento. A demanda de couro, como já foi mencionada, deu importância a um tipo bem conhecido. Coni (1986, p. 68) define o changador, o que precede o gaucho, como aquele que carneia o gado alheio com o objetivo de vender o couro e trocá-lo por qualquer coisa na pulpería. Neste lugar "nefasto", ele jogará o pouco que possui e se embriagará até cair no chão, isto se não houver alguma morte, o que fará com que tenha que fugir da justiça se embrenhando em algum mato. Este conjunto de coisas define um gaúcho. Vagabundos, changadores, gauderios e por último gauchos (CARRIL, 1993, p. 16). Nichols (1953, p.47) define da seguinte forma: "Sin un caballo para montar y una vaca para cazar no hubiera existido el gaucho". 


\section{Mapa de localização das estâncias missioneiras.}

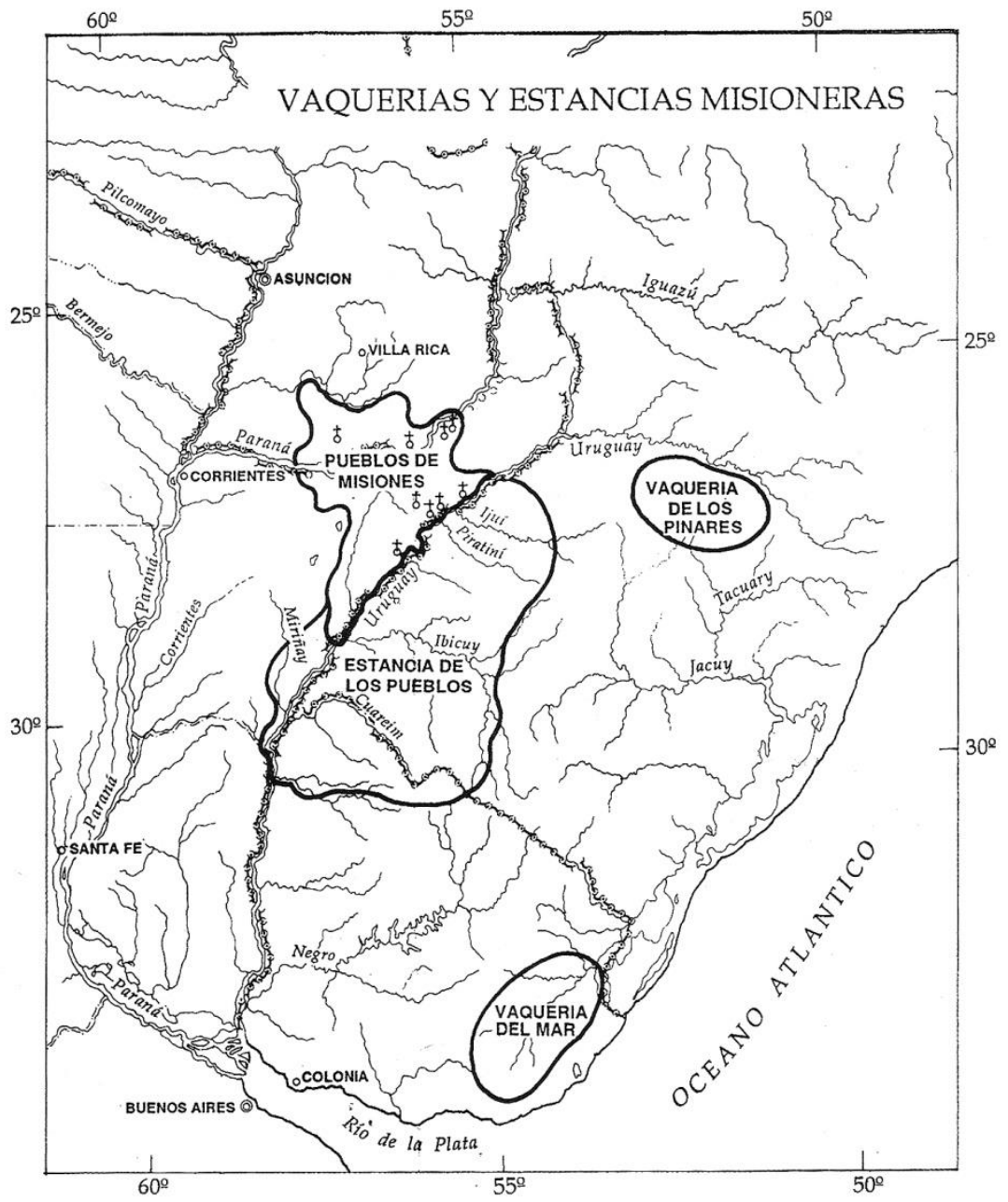

Fonte: Maeder e Gutiérrez (2009, p.06).

Este tipo normalmente solitário capturava o gado vacum retirando o couro de alto valor comercial. Havia se convertido em um intermediário entre esta mercadoria e os portugueses e seus aliados ingleses. Hábil na arte da equitação, levava a mercadoria para Colônia e, no retorno, assaltava as casas de espanhóis para roubar as mulheres.

Eram tratados como bandos de delinquentes. Identificavam-se como mestiços desgarrados, aqueles que não têm Deus, Rei e nem Lei. Mas dentro desta alternativa de vida na Banda Oriental, comercializavam entre seu grupo cachaça e tabaco, e desenvolveram "El habla del gaucho, parcialmente recogida por la literatura gauchesca, quedó así repleta de términos y expresiones provenientes a la vez de Portugal y España" (GALLARDO, 2007, p.83).

Isto forçou os jesuítas e os guaranis a organizarem suas estâncias de forma que seus rebanhos não fossem atacados. Todavia, a habilidade do gaucho, o manejo do posteiro e a organização militar do exército guarani, misturadas, dão 
origem ao mestiço peão, que é o conhecedor das lidas campeiras e que vai tocar as estâncias particulares. Pois ninguém há de pensar que foram os estancieiros (sesmeiros) que organizaram o sistema de produção!

Assim,

Después de desaparecido el gaucho real su figura ha sofrido por lo menos dos reencarnaciones interesantes. Una ha sido literaria y la segunda social [...] El habitat del gaucho pasó del campo a la ciudad [...] Sin embargo, el gaucho no parece haber partido para siempre. Está bien vivo en la moderna literatura del Plata, en la música, en el arte. El gaucho real ha desaparecido hace tiempo, pero el gaucho sublimado y los ideales que él encarna viven aún (NICHOLS, 1953, p. 106-7).

Interessante que Madaline Nichols, em 1953, já percebia esta mudança do gaúcho para a cidade, uma vez que no campo não há mais condições para o seu modo de vida.

Colônia do Sacramento se tornou um grande problema para Buenos Aires. Os gauchos atacavam as estâncias castelhanas bem como as lusas, e o quadrante oeste jesuítico era autônomo demais na opinião das Coroas Ibéricas, em uma experiência que chamou a atenção de Montesquieu e Voltaire pela relação comunal em que viviam a sociedade e a terra.

Desenhava-se aí o Tratado de Madri. A permuta do território das Missões, para Portugal, pela Colônia do Sacramento, para Espanha, organizando a configuração territorial que se estabilizou. Para a devolução dos Sete Povos das Missões foram necessárias as forças das duas Coroas, que submeteram aos seus interesses os índios, após a Guerra Guaranítica, e os jesuítas, pela expulsão da Companhia de Jesus dos territórios lusos e espanhóis.

O desmonte das Missões na Banda Oriental ofertou uma grande quantidade de índios, terras e gado. Os primeiros não voltam para a mata, sendo absorvidos como uma mão de obra qualificada pelas estâncias privadas que avançaram sobre as terras das antigas estâncias comunais, se apropriando do gado que ali se encontrava. O gaucho também vai se sujeitar à condição de peão, pois o seu alistamento para as batalhas e o fechamento dos campos, impedindo suas cavalgadas, acabam com sua atividade. Como escreveu Gallardo (2007, p.86), "Sólo el matrero, el gaucho malo, prolongará por algún tiempo en forma individual la figura mítica y tenebrosa del gauderio, y el nombre de gaucho pasará a antónimo de su viejo significado".

Durante todo o período dos saladeros, ou das charqueadas, que surgiram na mesma época, ao fim dos anos 1700, o sistema de produção foi totalmente inspirado 
no modelo missioneiro. Todos os valores cultuados do gaúcho, caráter (del gaucho bueno, por supuesto!), vestimentas, bravura, desprendimento, liberdade, destreza na lida campeira e na vida, foram fundados no modo de vida desenvolvido neste período.

\section{Da introdução das raças europeias na Argentina até a possibilidade da frigorificação}

A introdução das raças europeias na Argentina passa pela possibilidade da Inglaterra produzir arame em escala industrial. Comumente a cerca é vista como um demarcador da propriedade. O que define a propriedade é a relação daquele que se diz proprietário com o poder e a sua legitimidade. No mundo prático a cerca separa a criação, pois a lavoura não a necessita.

A introdução de raças britânicas na Argentina soma a possibilidade de demarcação de terras e a consequente separação dos rebanhos, com a associação de criadores chamada de vanguardia ganadera. Para Sesto (2005, p. 39), "Llamaremos vanguardia ganadera a un grupo de cincuenta terratenientes que fue el agente social portador de esta genética en carnes vacunas". Este grupo de amigos formou-se a partir de 1850, trazendo exemplares puros de pedigree Shorthorn e Hereford entre 1856 e 1866. "Para este círculo de amigos fue fundamental la clarividencia de la generación de sus padres, que - al igual que Ricardo Newton resolvieron enviarlos a Europa para adquirir los conocimientos indispensables" (SESTO, 2005, p.41). Newton foi quem introduziu em suas estâncias o primeiro alambrado, juntamente com o melhoramento de raças bovinas e ovinas, estas para o melhor aproveitamento da lã. Também foi vice-presidente da Sociedade Rural Argentina, criada em 1866, e ganhador de prêmios na Segunda Exposição Internacional de Paris, em 1867 (SBARRA, 2008, p. 41).

Sesto (2005, p. 163) chama a atenção para o detalhe de que a partir destes anos, "El salto cualitativo en rindes, palatabilidad y calidad carnicera sólo empezó a tomarse en cuenta para producir biotipos para exportación entre 1887 y 1894, aunque la meta de $600 \mathrm{~kg}$ a los cuatro años y carnes marmoreadas se alcanzó entre 1895 y 1900." Esta mudança no sistema de produção com a introdução de touros britânicos traz a preocupação com a produtividade, ou seja, a produção medida em quilo - hectare - ano, e o sabor pelo teor de gordura na carne. Todavia, esta produtividade se dá aos poucos. 
A autora chama a atenção para os riscos de adaptação das raças Shorthorn (Durham), Hereford e Aberdeen Angus quanto à sua climatização. A estratégia da vanguardia ganadera foi o aprimoramento de um tipo de rebanho voltado para a exportação de carnes de primeira, enquanto experimentava uma mistura de raças britânicas com crioulas para o melhoramento e adaptação, esta para consumo interno. Assim, Sesto (2005, p. 199-202) aponta que a situação do rebanho vacum em 1881 era composta por puros (britânicos) 0,4\%, mestizos 9\% e criollos $91 \%$. Já em 1895 a situação mudou para puros 1\%, mestizos 50\% e criollos $49 \%$.

Para Tarruella (2012), o surgimento da Sociedade Rural Argentina é fundamental para um novo modelo de gestão no campo. Ao grupo original da Vanguardia soma-se Ricardo B. Newton, o introdutor do alambrado na Argentina, acrescentando algumas transformações no projeto. No ano de criação da Sociedade, o preço da lã cai no mercado mundial devido a uma sobreoferta dos países produtores, Argentina, Uruguai, Austrália e Nova Zelândia. É neste momento que

La Sociedad Rural insistió em la necesidad de convertir a los grandes terratenientes de Buenos Aires en líderes de un processo de reforma rural que buscaban transformar tanto al proprio empresariado como al médio en el actuava, y que encontraba em los modelos de sociedade y de tecnologia agraria del hemisferio norte - Inglaterra en primer lugar, pero tambíen Francia, Estados Unidos y Alemania - sus principales referencias innovadoras (TARRUELLA, 2012, p.117).

Conjuntamente à introdução do alambrado e da efetiva introdução de raças de gado vacum na Argentina, também se dá o processo de gestão empresarial, buscando o melhoramento na produtividade e a adequação aos mercados de interesse. Mais adiante o autor destaca que,

Por eso, la aparición del frigorífico jugó un papel central en la provisión de carnes al Reino Unido y los productores argentinos proveyeron alimentos durante las guerras de principios del siglo XX [...] También se registró una renovación de razas y calidades a través del mestizaje hacia fines del siglo XIX (TARRUELLA, 2012, p.131).

Os ingleses dominaram o mercado frigorífico, ampliando a rede ferroviária conjuntamente até 1907, quando perdem o domínio para os Estados Unidos. Em 1866 é fundada a Sociedade Rural Argentina e em 1875 o Estado doa 12 hectares no bairro de Palermo, na cidade de Buenos Aires, para a construção do espaço da Feira de Exposições ( La Rural), que começa como uma exposição ganadeira onde rapidamente é acrescentada a exposição de máquinas agrícolas que aumentam a 
produtividade da lavoura e da pecuária. Esta feira serviu de inspiração para a EXPOINTER (Exposição Internacional no Rio Grande do Sul), com o mesmo objetivo, ou seja, divulgar e promover a elevação do patamar técnico na atividade agrícola.

Já a penetração dos frigoríficos no estado do Rio Grande do Sul se deu a partir de 1917. O melhoramento dos rebanhos no Rio Grande do Sul começa na época do cercamento das terras, por volta de 1870.

Os frigoríficos multinacionais, a partir de 1917, compraram alguns estabelecimentos saladeiros, transformando-os para a atividade frigorífica.

A Armour, em Santana do Livramento (RS), adquiriu a charqueada Irigoyen para transformá-la em frigorífico. Instalou-se próximo da matéria-prima, os rebanhos da Campanha de melhor qualidade, e exportava pelo porto de Montevidéu, aproveitando os baixos custos da infraestrutura ferroviária e portuária do Uruguai. $\mathrm{O}$ refinamento de raças no rebanho sulino já estava em andamento e, com a entrada dos frigoríficos, este processo de seleção e cruzamento aprofundou-se, bem como os cuidados com a saúde e higiene animais (PESAVENTO, 1980,132-3).

Seguindo os passos da Armour, o frigorífico Wilson valeu-se da mesma estratégia. A Swift comprou um terreno em Rio Grande e construiu um cais junto ao porto, adquirindo gado do litoral e também da Campanha, principalmente de Bagé (PESAVENTO,1980, p.138-140).

Este cenário fez com que o rebanho sul-rio-grandense se diferenciasse. Esta situação teve seu auge nos anos 1960, decaindo e entrando em colapso nos anos 1980, para se recuperar na década seguinte, mas de uma forma bem diferente.

\section{Da pecuária bovina de corte à verticalização}

A pecuária bovina tradicional é aquela em que se produz de forma extensiva, priorizando a compra de campos, com pouca inovação, pouco investimento em benfeitorias e genética, sem associação com a lavoura (apenas em caso de arrendamento) e tempo médio de abate de 4,5 anos. Esta é a base da sociedade latifundiária patrimonialista, com pouca divisão do trabalho e possibilidade de ascensão social, fruto de uma classe dominante rural em função do monopólio da terra.

Já a atividade pecuária empresarial produz de forma intensiva, com inovações no sentido de diminuição do tempo de produção e aproveitamento da 
mais-valia, investimento em genética, benfeitorias, associação com lavouras intensivas como as de arroz, soja e forrageiras de inverno próprias ou em sociedade, e tempo médio de abate entre 16 e 24 meses. É o local da produção de carnes de grife, chamadas de "terneiro precoce". Com o aumento da divisão do trabalho, resultado da integração lavoura-pecuária, aumenta a oferta de trabalho permanente e temporário nas unidades de produção, bem como do serviço técnico especializado, este com base urbana, integrando o campo e as cidades médias. A empresa rural representa a atividade capitalista por excelência, com uma racionalidade e organização do trabalho voltada para o lucro. O trabalho assalariado ocorre com frequência sazonal, sendo o número de trabalhadores temporários maior que o de permanentes.

Ainda que sem uma ruptura significativa com a oligarquia rural, esta nova classe de empresários lidera a condução e a representação das relações capitalistas e de mercado no campo a partir dos anos 1990. Dinamiza os centros urbanos onde se situa. Trabalha com pecuária e lavoura integradas, diferente dos lavoureiros, que apenas plantam, e dos pecuaristas tradicionais, que apenas criam.

Esta classe de produtores rurais da atividade pecuária, que gerencia suas estâncias como empresas, poucas semelhanças guarda com os analisados anteriormente. Portanto, a mudança de paradigma na produção pecuária não se restringe apenas à introdução de tecnologia na atividade pecuária, mas a uma mudança de comportamento de seus atores sociais e sua participação junto ao mercado. A integração lavoura-pecuária faz do pecuarista um agricultor antes de um criador.

O melhoramento da pastagem nativa é o primeiro passo. Aumentar a oferta de alimento dividindo os campos em mais potreiros de forma a permitir que a pastagem se recupere. A integração com a lavoura aumenta a oferta de alimento, permitindo um aumento do ganho médio de peso do animal, bem como uma utilização mais racional das máquinas da empresa.

O objetivo geral do sistema é o de aumentar a natalidade e diminuir o tempo de abate, principais problemas da pecuária tradicional, encurtando o tempo de investimento de capitais, permitindo o ciclo completo, ou seja, cria, recria e engorda. Para alcançar este objetivo é necessária a integração das variáveis: sanidade, manejo, genética e alimentação.

A integração da pecuária com os demais setores da economia a montante e a jusante é fundamental para consolidar a tecnificação da atividade. 
A novidade é a expansão dos negócios que envolvem a genética pecuária, que já ocorriam na Argentina, passando a atuar também no Brasil. A montante, a pecuária utiliza todos os implementos e recursos da lavoura, mais os recursos oriundos da indústria genética - incluindo-se aqui as conexões - que fornece as matrizes que, adaptadas e em condições adequadas, irão transformar terneiros saudáveis em bois gordos em menor tempo que a pecuária tradicional.

Já a jusante, quem se beneficia é o setor atacadista, principalmente as grandes redes de supermercados e frigoríficos, que passaram a ter grifes de carnes, distinguindo-se pela qualidade do produto, ocupando o espaço de antigos retalhistas (açougues), monopolizando ou oligopolizando o setor, mundialmente, inclusive.

Ou seja, ao contrário do sistema anterior, onde os frigoríficos dominavam o setor de carnes, agora o sistema é integrado pelos setores de genética - que formam as raças que obtêm melhores resultados (integração vertical) - com os produtores que aderem a uma conexão e produzem a carne (integração horizontal), e participam de um programa de comercialização de carnes de grifes ou exportação (frigorífico e atacado, integração vertical).

Este sistema de produção de integração lavoura-pecuária bovina, utilizando pastagens e forrageiras, é encontrado na Argentina, Uruguai, Austrália, Nova Zelândia e Brasil, sendo que no Rio Grande do Sul estão sediadas as principais conexões de raças europeias. Um mercado único no mundo.

Entretanto, com um mercado globalizado, apenas produzir carne de qualidade já não é o suficiente. É preciso achar um lugar no mundo!

Lefebvre (2002, p. 15) denomina "Sociedade urbana" a sociedade que nasce da industrialização, como a sociedade que domina e absorve a produção agrícola em sua constituição.

Para denominar a sociedade pós-industrial, ou seja, aquela que nasce da industrialização e a sucede, propomos aqui este conceito: sociedade urbana, que designa, mais que um fato consumado, a tendência, a orientação, a virtualidade. Isso, por conseguinte, não tira o valor de outra caracterização crítica da realidade contemporânea como, por exemplo, a análise da "sociedade burocrática de consumo dirigido" (LEFEBVRE, 2002, p. 16).

O campo passa a ser uma extensão da cidade, sua "circunvizinhança", seu horizonte, seu limite. A forma de produzir se alia ao modo de vida urbano, ou seja, como e para quem produzir. Assim, a produção mais tecnológica (conhecimento) passa a dirigir-se para um público urbano que cria vínculos identitários com esta forma de consumo. 
Ao analisar a sociedade contemporânea, Featherstone (1995, p.121-2) envolve "a dimensão cultural da economia, a simbolização e o uso de bens materiais como 'comunicadores', não apenas como utilidades". Isto significa que o consumo não deve ser entendido apenas como valor de uso ou de troca, mas, também, como um consumo de signos, revendo o papel da cultura na reprodução do capitalismo contemporâneo. Para o autor, "a estetização da realidade coloca em primeiro plano a importância do estilo", criando um imaginário associado ao estilo de vida. Ou seja, o topo da pirâmide do consumo, onde não basta um nível de renda mais elevado, mas também um julgamento dos bens e serviços para o consumo, bem como uma disponibilidade de tempo para isto. Em resumo, usando a expressão de Bourdieu, "o gosto classifica, e classifica o classificador" (FEATHERSTONE, 1995, p. 37-8). Não é o consumo, mas o quê e de onde você consome.

Harvey (2005) analisa a exclusividade de alguns produtos, como quadros de artistas famosos, vinhos e cervejas de regiões conhecidas, abordando do ponto de vista de criar uma possibilidade de ganho de renda a partir do monopólio de um determinado produto de um determinado lugar. Ou seja, a possibilidade de se obter um ganho a mais daquele criado pelo trabalho, aquele criado pela exclusividade do lugar. "Procura preservar rendas monopolistas, sustentando as virtudes exclusivas da terra, do clima e da tradição (virtudes reunidas sob o termo francês terroir) e a distinção do produto, certificada por um nome" (HARVEY, 2001, p. 227). Transformar as práticas regionais num modo de vida e de consumo.

Para que isto de fato ocorra, é necessário que as relações local-global estejam desenvolvidas a ponto de que as atividades praticadas em um lugar possam ser consumidas, trocadas, mercantilizadas em outro. Por isto, Harvey (2005) escreve que é um equívoco achar que a globalização exerce uma força sobre o desenvolvimento local. Sendo assim,

\footnotetext{
Neste caso, o que está em jogo [...] é um relacionamento mais complicado através das escalas, em que as iniciativas locais podem alcançar uma escala global e vice-versa, ao mesmo tempo que certos processos, dentro de uma definição específica de escala - competição interurbana e inter-regional podem reelaborar as configurações local/regional da globalização. Portanto, não se deve ver a globalização como uma unidade indiferenciada, mas sim como uma padronização geograficamente articulada das atividades e das relações capitalistas globais (HARVEY, 2005, p. 230).
}

Mesmo existindo uma relação dialética do local com o global, o lugar (real, concreto) se insere junto a outros lugares criando a noção de globalização (abstrato), ou seja, uma prática urbana própria da sociedade pós-industrial, esta sim, 
mundializada. São as ações cotidianas que dão a noção do modo de vida urbano e suas técnicas. Em nosso caso, a produção e consumo de carne bovina e seus sistemas de produção. Os sistemas de produção atuais se inserem em uma sociedade flexível, com estilos de consumo relacionados ao lugar. Com a carne bovina não é diferente.

\section{Alianza del Pastizal (à guisa de conclusão)}

No sentido de sintetizar e ilustrar o tema apresentado tomaremos como exemplo a Alianza del Pastizal (http://www.savebrasil.org.br/pampa/). Esta Alianza foi criada no sentido de promover a biodiversidade e a conservação do Bioma Pampa. Por iniciativa da Bird Life International, em conjunto com a SAVE Brasil, Aves Argentinas, Guyra Paraguay e Aves Uruguay, "As ações têm por objetivo integrar o desenvolvimento do Pampa com a conservação da biodiversidade, por meio da promoção de técnicas de manejo favoráveis ao meio ambiente".

Em outro sítio, mas do Frigorífico Marfrig, temos a seguinte manchete:

“Alianza del Pastizal e Marfrig Lançam Selo para Valorizar a Carne Produzida em Propriedades que conservam os Campos Nativos do Bioma Pampa"

(http://www.marfrig.com.br/pt/documentos?id=731). Acesso em: 18 jan. 2019.

O texto anunciava o lançamento do respectivo selo em parceria com o frigorífico durante a 38ํㅡㄹ EXPOINTER, em 2016, valorizando a carne produzida em propriedades que conservam áreas de campos nativos do Bioma Pampa, e oferecendo um produto que reúne a "oportunidade de promover um produto com garantia de origem, que valoriza o trabalho e a tradição do Pampa, assim como incentiva boas práticas de conservação da biodiversidade deste bioma tão importante no Brasil", explica um gerente.

O sítio ainda traz informações sobre a Alianza del Pastizal, que trabalha diretamente com os produtores rurais, desenvolvendo linhas de ação para valorizar os mais diferenciados sistemas de produção, colaborando, assim, para o desenvolvimento social e econômico e para a conservação da natureza, "com seus bens e serviços ambientais como manutenção da biodiversidade, redução de efeito estufa, conservação de recursos hídricos e manutenção da identidade cultural do gaúcho." (http://www.marfrig.com.br/pt/documentos?id=731).

Temos aqui um texto que contempla muito bem a noção de terroir, que une as práticas humanas e sua adaptação ao meio, em equilíbrio. Ou seja, um modo de 
vida, e suas práticas e técnicas compatíveis com a exploração do meio, caracterizando um sistema de produção utilizado em uma região (sistema agrário). Diferentes lugares integrados por um sistema verticalizado internacionalmente.

Ao mesmo tempo, "O selo da carne da Alianza del Pastizal permitirá aos consumidores identificar e selecionar uma carne produzida de forma alinhada à conservação do meio ambiente, que preserva importantes superfícies de campos nativos, vegetação original e predominante dos Pampas sul-americanos." $O$ consumidor pode ter a certeza de que, além de um produto saudável, rico em Ômega 3, estará, também, contribuindo para a manutenção do ambiente. "O selo é concedido por meio de um processo de avaliação e certificação dos processos produtivos nas propriedades rurais membros da Alianza del Pastizal seguindo as diretrizes estabelecidas pelo Conselho de Cerificação de Carnes del Pastizal (CCCP)". No Rio Grande do Sul, o programa já totalizava uma área de 120 mil hectares, dos quais 80 mil em campo nativo.

Apenas para lembrar, A Marfrig assumiu em 2009 o compromisso público com o Greenpeace de assegurar a compra de gado legal e de combater o desmatamento no bioma Amazônia. (http://www.marfrig.com.br/pt/marfrig-global-foods/historia)

No 1ㅇ Remate de Gado da Alianza del Pastizal (http://www.savebrasil.org.br/realizado-o-10-remate-de-gado-da-alianza-del-pastizal/) realizado pelo Sindicato Rural de Lavras do Sul, sede do programa no Brasil, já houve valorização dos animais negociados, bovinos e ovinos, devido ao fato de estes serem criados em estabelecimentos que cultivam, pelo menos, $50 \%$ de campos nativos, certificados pela Alianza del Pastizal e avaliados com o ICP (Índice de Conservação de Campos Naturais).

Esta mudança qualitativa no sistema de produção, que já buscava um aumento de produtividade, vem agora acrescentar uma comunicação com o consumidor, ou seja, uma produção compatível com a manutenção do meio explorado.

Este tipo de bovinocultura e formação de pastagens trabalha muito com a paisagem, explorando imagens de pássaros nativos e em extinção, com o objetivo de associar a produção ao bioma, bem como à tradição em que está inserida. $O$ município de Lavras do Sul foi escolhido como base da Alianza porque até a década dos anos 2000 era o que mantinha maior área de campos nativos. Apesar da boa iniciativa e dos envolvimentos globais do lugar, o programa não impediu que a área plantada de soja passasse de 6.000 ha, em 2004, para 20.000 ha em 2017. 
(https://cidades.ibge.gov.br/brasil/rs/lavras-do-sul/pesquisa/14/10193?ano=2004)

(https://cidades.ibge.gov.br/brasil/rs/lavras-do-sul/pesquisa/14/10193?ano=2017).

Isto se deu pelo avanço do plantio direto da soja em municípios que estão sobre o escudo cristalino, ou Planalto Sul-rio-grandense, onde havia restrições ao plantio com arado.

De qualquer forma, o Brasil possui o segundo maior rebanho bovino mundial, com cerca de 172 milhões de cabeças, estando atrás da Índia apenas, e bem à frente dos demais países produtores, segundo dados preliminares do Censo Agropecuário 2017. Também o Rio Grande do Sul tem uma população bovina de 11,5 milhões de cabeças, aproximadamente, sendo o $6^{\circ}$ maior rebanho. (https://censos.ibge.gov.br/agro/2017/templates/censo_agro/resultadosagro/pecuaria .html). Outros sítios de publicações especializadas, estaduais e nacionais, apontam para um número maior que estes para ambos.

Todavia, podemos regionalizar a pecuária bovina brasileira em quatro regiões:

a) O Norte, com seus rebanhos em área de formação de pastagens recentes, contestadas por suas práticas em áreas florestais;

b) O Centro-Oeste, com predomínio de rebanhos zebuínos, mas de sistemas de produção semelhantes aos utilizados no Sul;

c) A região de Minas Gerais, que concentra a pecuária leiteira;

d) Sul do Brasil e Rio Grande do Sul, especialmente, onde se concentra a pecuária empresarial com rebanhos de raças europeias, confundindo-se com a região do Prata.

Com todo o potencial exportador de carnes, e poderiam se somar aqui aves e suínos, o Brasil tem uma grande capacidade de produção e exportação de carnes para o mundo. Boa parte deste processo envolve muita tecnologia a montante e a jusante da produção. A produção de ponta está no sul do Brasil, acompanhando, mais uma vez, as transformações ocorridas no Pampa.

A produção da pecuária bovina moderna não pode mais ser entendida a partir da produção em si. Após cinco séculos de exploração da atividade pecuária bovina na região do Pampa, ainda hoje sua imagem está associada às pradarias onde pastam tranquilamente os animais trazidos outrora de outro continente. Práticas que consolidaram um modo de vida, e que passaram, com o tempo, a serem vividas mais na cidade que no campo.

Entretanto, não se confunde com as demais regiões. O Pampa é único. E traz consigo, principalmente no imaginário urbano, o acúmulo das tantas mudanças nos 
sistemas de produção e dos personagens que se envolveram ao longo da história. Sim, o Pampa é antes de qualquer coisa um terroir do gado bovino.

\section{REFERÊNCIAS}

BRUXEL, Arnaldo. O gado na antiga Banda Oriental do Uruguai. Porto Alegre: Instituto Anchietano de Pesquisas, 1961. Cap. 5 e 6.

Os trinta povos guaranis. Porto Alegre: Sulina, 1978.

CACCIATORE, Fernando. A origem do gaúcho e outros ensaios. Porto Alegre: Buenas Ideias, 2017.

CANABRAVA, Alice Piffer. O comércio português no Rio da Prata (1580-1640). Belo Horizonte: Itatiaia, 1984.

CARRIL, Bonifacio del. El Gaucho. Su origen. Su personalidad. Su vida. Buenos Aires: Emecé Editores,1993.

CONI, Emilio. A. Historia de las vaquerias de Rio de la Plata. 1555-1750. Buenos Aires: Platero, 1979.

. El Gaucho. Argentina, Brasil,Uruguay. Buenos Aires: Ediciones Solar, 1986. FEATHERSTONE, Mike. Cultura de consumo e pós-modernismo. São Paulo: Studio Nobel. 1995.

FONTOURA, Luiz Fernando M. Macanudo Taurino: uma espécie em extinção? São Paulo, USP, Tese de doutorado, 2000.

GALLARDO, Jorge Emilio. Contexto criollos de Río de la Plata. La redención del gaucho. Buenos Aires: Idea Viva, 2007.

GILBERTI, Horacio. C. Historia económica de la ganaderia argentina. Buenos Aires:

Ediciones Solar, 1986.

HARVEY, David. A produção capitalista do espaço. São Paulo: Annablume, 2005.

LEFEBVRE, Henri. A revolução urbana. Belo Horizonte: Ed. UFMG, 2002.

LUGON, Clovis. A República “Comunista” Cristã dos Guaranis. 1610/1768. 2ª ed. Rio de Janeiro: Paz e Terra, 1976.

MAEDER, Ernesto. \& GUTIERREZ, Ramón. Atlas territorial y urbano de las missiones jesuíticas de guaraníes. Argentina, Paraguay y Brasil. Sevilla: Consejo de cultura, 2009.

MARQUES, Alvarino. Episódios do ciclo do charque. Porto Alegre, EDIGAL. 1987.

MAZOYER, Marcel. \& ROUDART, Laurence. História das agriculturas no mundo: do neolítico à crise contemporânea. São Paulo: editora da UNESP; Brasília: NEAD, 2010.

NICHOLS, Madaline W. El Gaucho. Buenos Aires: Ediciones Peuser, 1953.

PESAVENTO, Sandra. República Velha gaúcha: charqueadas, frigoríficos, criadores. Porto Alegre, Movimento/IEL. 1980. 
. História do Rio Grande do Sul. $7^{a}$ ed. Porto Alegre: Mercado

Aberto, 1994.

SBARRA, Noel H. Historia del alambrado en la Argentina. 5a ed. Buenos Aires: Letemendia, 2008.

SESTO, Carmen. Historia del capitalismo agrario pampeano: la vanguardia ganadera bonaerense, 1856-1900. Buenos Aires: Siglo XIX Argentina, 2005.

SORRE, Max. Geografia Humana. Introdução. Niterói: Revista Geographia, Vol. 5, № 10, 2003. Disponível em: http://periodicos.uff.br/geographia/article/view/13461/8661. Acesso em 16 de jan de 2019.

TARRUELA, Alejandro C. Historia de La Sociedad Rural Argentina. Buenos Aires: Planeta, 2012.

VERDUM, Roberto, FONTOURA, Luiz Fernando M. Temáticas rurais: do local ao regional. Porto Alegre: Editora da UFRGS, 2009.

WILLIMAN, José C. \& PONS, Carlos P. La Banda Oriental en la lucha de los Imperios. 1503-1810. Montevideo: Ediciones de La Banda Oriental, 2011.

\section{NOTAS DE AUTOR}

\section{CONTRIBUIÇÃO DE AUTORIA}

Luiz Fernando Mazzini Fontoura - Concepção. Coleta de dados, Análise de dados, Elaboração do manuscrito, revisão e aprovação da versão final do trabalho.

\section{FINANCIAMENTO}

Não se aplica.

CONSENTIMENTO DE USO DE IMAGEM

Não se aplica.

APROVAÇÃO DE COMITÊ DE ÉTICA EM PESQUISA

Não se aplica.

CONFLITO DE INTERESSES

Não se aplica.

\section{LICENÇA DE USO}

Este artigo está licenciado sob a Licença Creative Commons CC-BY. Com essa licença você pode compartilhar, adaptar, criar para qualquer fim, desde que atribua a autoria da obra.

\section{HISTÓRICO}

Recebido em: 28-01-2019

Aprovado em: 20-02-2019 